\title{
Dutch flood protection policy and measures based on risk assessment
}

\author{
Richard Jorissen $^{1,2, a}$, Erik Kraaij ${ }^{1,3}$ and Ellen Tromp ${ }^{1,4}$ \\ ${ }^{1}$ Dutch Flood Protection Programme, PO Box 2232, 3500 GE Utrecht, The Netherlands \\ ${ }^{2}$ Ministry of Infrastructure and Environment, The Netherlands \\ ${ }^{3}$ Dutch Association of Regional Water Authorities, The Netherlands \\ ${ }^{4}$ Deltares, The Netherlands
}

\begin{abstract}
The Dutch Flood Protection Programme (DFPP) of The Netherlands is aimed at improving flood protection structures up to the newly derived safety standards. It is expected that roughly $50 \%$ of the primary flood protection structures need reinforcement with respect to newly derived safety standards. On a national level the necessary projects are ranked based on the actual flooding risk and fitted within the budget constraints. Additional goals of the DFPP are to improve performance in project management, to enhance the quality of more integral solutions and to expand the cooperation between all authorities involved. The DFPP is an alliance of the Dutch Water Authorities and the Ministry of Infrastructure and Environment, but also a methodology in which the Ministry, regional water authorities, scientific institutes, consultancy and construction companies participate.
\end{abstract}

\section{Introduction}

The Netherlands is a small country, lying in the delta of several rivers (Rhine, Meuse, Scheldt) and bordering the North Sea (figure 1). On the one hand, it's a densely populated country and very vulnerable to flooding. Nearly $60 \%$ of the land, $70 \%$ of the population (total 17 million people) and $70 \%$ of the economy (total GDP 650 billion $€$ ) are flood prone [1,2,3].

On the other hand the Dutch have a long tradition of water management. Strict safety standards, dedicated forms of governance (including taxation), regular safety assessments and sound engineering have yielded a wellprotected country. The flood prone areas are safe guarded from flooding by approximately 3800 kilometres of primary flood protection structures (figure 2). About $90 \%$ of these structures are managed by regional water authorities, whereas the remaining structures are managed by the national water authority (Rijkswaterstaat, part of the Ministry of Infrastructure and Environment).

The primary flood protection structures are found along the major rivers, large lakes, estuaries and the coast. The majority of primary flood protection structures are typical dikes. In addition to this structures (such as locks, gates and barriers) are used. Along the coast the dunes provide a natural protection against flooding, albeit that also this type of protection needs maintenance and in some cases reinforcement.
The total length of dikes in The Netherlands is over 22,500 kilometres, but the majority of these dikes are used for regional water management purposes [4].

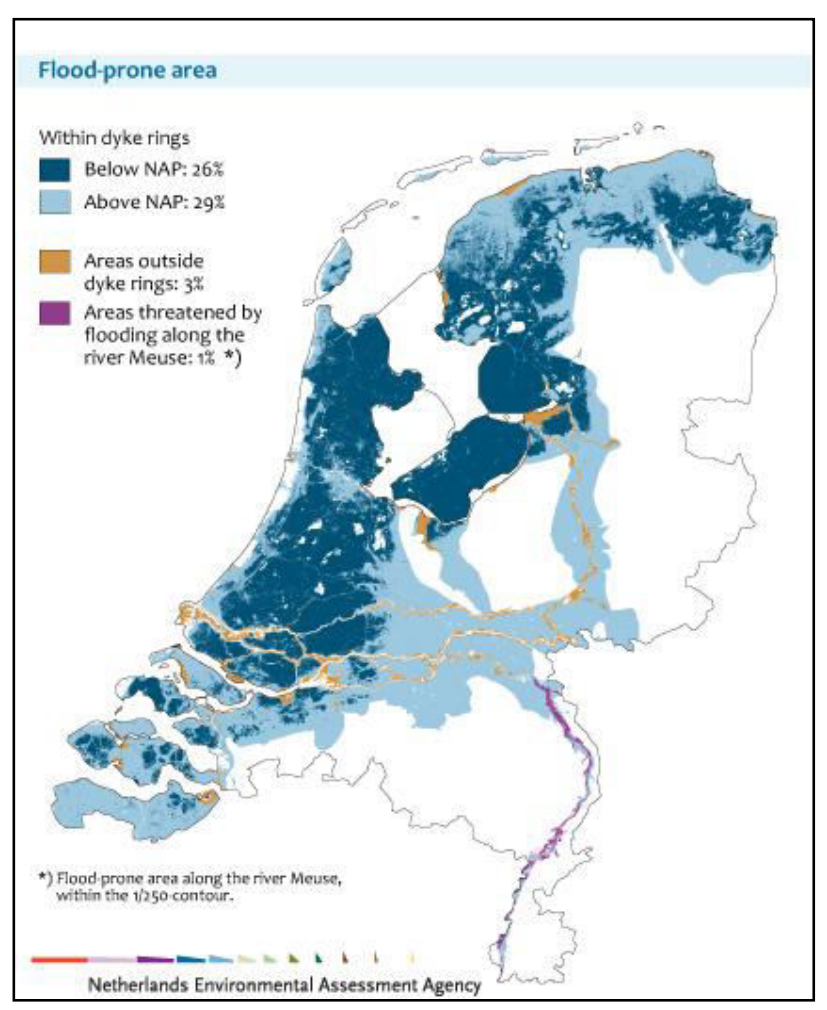

Figure 1 The Netherlands [3]

\footnotetext{
${ }^{\mathrm{a}}$ Corresponding author: richard.jorissen@hoogwaterbescherming.nl
} 


\section{Safety standards and reinforcement projects}

\subsection{General}

Together, the primary flood protection structures protect 94 dike ring areas (figure 2). Each dike ring area has a legally prescribed required level of flood protection. Protection levels vary $1 / 250$ per year for the dike ring areas along the upper reaches of the river Meuse to $1 / 10000$ per year for the most densely populated areas in the western part of the country.

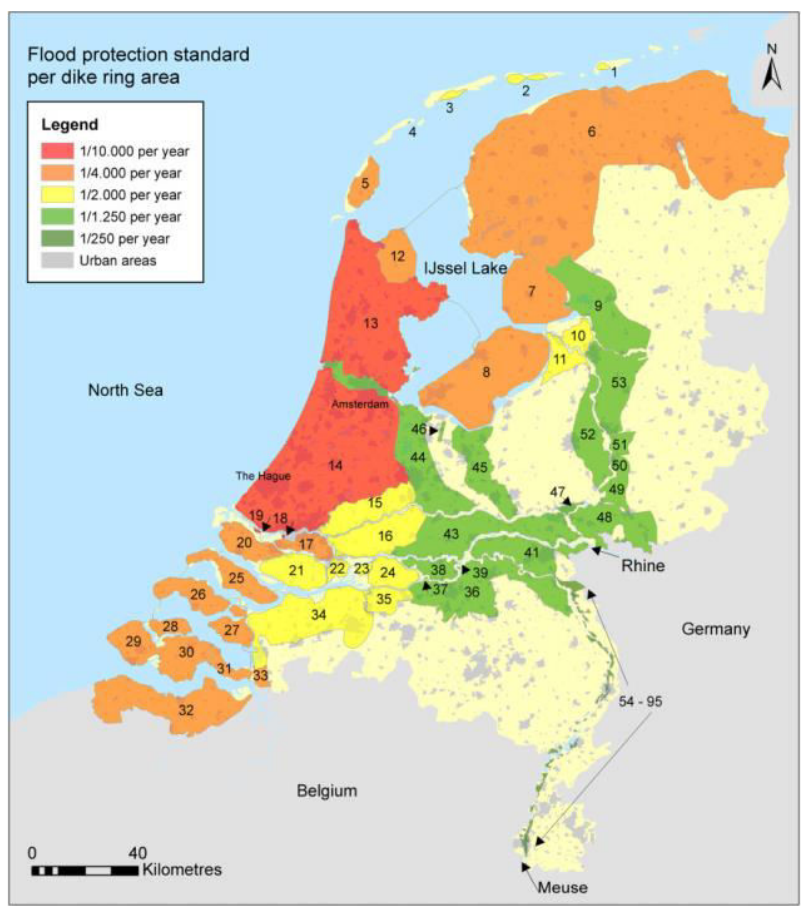

Figure 2 Dike ring areas

The foundation of these flood protection standards was laid by Van Dantzig and Kriens [5,6]. Their work contributed to the report of the first Delta Committee (1956-1960). This Delta Committee was installed by the Minister of Public Works and Water Management after the disastrous flood of 1953 in the south-western part of the Netherlands (1836 casualties and economic loss of approximately $10 \%$ GDP). The Committee proposed safety standards based on a cost-benefit analysis. This analysis was carried out for dike ring area 14, Central Holland, because this is the most densely populated dike ring area. The result was a flood protection standard of $1 / 10000$ per year for dike ring area 14. Every flood protection structure surrounding this dike ring area should be designed in order to withstand the hydraulic loads associated with the safety standard. In terms of water levels this meant that the design water level was MSL+5 metres, exceeding the flood level of 1953 (MSL+3,85 metres).

Using this result the flood protection standards for the other coastal dike ring areas were established by comparing estimated potential flood damages. Later the flood protection standards for the other dike ring areas were established based on various policy analyses, yielding $1 / 2000$ for the tidal river areas, $1 / 1250$ for the majority of the river area and 1/250 for the upper reaches of the Meuse.

The balance between vulnerability and flood protection is not a static one [7]. Climate change, socioeconomic developments and research \& innovation require an evaluation of the safety standards.

\subsection{Safety assessment and reinforcement projects}

Based on the safety standards large flood protection projects were carried out during the decades after the flood of 1953. In 1996 the Flood Protection Act marked a conclusion of this period: the technical safety standards became statutory and all flood protection structures were to be tested against these standards every 5 (later 6) years. This comprehensive system differs from the situation in our neighbouring countries $[8,9,10]$. It was expected that the focus of the flood protection efforts would be aimed at operation and maintenance.

However, this was proved to be otherwise quite soon. The first assessment (concluded in 2001) was more or less a test round but the second assessment (concluded in 2006) yielded a significant reconstruction programme of 370 kilometres (roughly $10 \%$ of the total). Most of these reconstruction projects were caused by increased hydraulic loads and new insights in technical criteria.

The reconstruction programme was initially started in the traditional way: regional water authorities conduct their projects and the reconstruction costs are fully subsidized by the Ministry. Evaluation of this programme and earlier reconstruction projects showed that considerable improvements in effectiveness and efficiency were necessary. A Taskforce lead by Ten Heuvelhof [11] recommended the authorities to change the financial arrangement for reconstruction projects, to share the responsibility for the programme, to improve the preparation of projects (including an exploration phase) and to invest in technical and project management skills by the regional water authorities.

Regional water authorities took their responsibility and in 2011 a Governance Agreement on Water was reached [12]. For flood protection the regional water authorities committed themselves to co-financing (50\%) the reconstruction works and to improve effectiveness and efficiency. With this agreement the regional water authorities and the Ministry have laid the foundation for a joint programme, the Dutch Flood Protection Programme (DFPP). The goal of the DFPP is to improve flood protection structures that do not meet the required safety standards. The initial scope of the DFPP is 748 kilometres and was determined by the third safety assessment (completed in 2011-2013). 


\section{Delta Programme}

\subsection{General}

In 2008, the second Delta Committee, commissioned by the Secretary of Public Works and Water Management, provided recommendations on how to defend the Netherlands against the expected impacts of climate change, such as sea level rise, longer periods of drought, more intense periods of rainfall and additional land subsidence over the coming two hundred years [13]. The Delta Programme was announced in September 2008 based on these recommendations.

The Netherlands needs to prepare for the consequences of the rising sea level, land subsidence and rising temperatures. This means looking further ahead and making effective plans for the long-term. The Delta Programme is designed to prevent disasters and to provide sufficient freshwater supplies, now and in the future. It's not only about the future, however. Flood protection currently also falls short in some areas. The government is carrying out a number of projects to remedy this. These projects are included in the annual Delta Programme. The yearly financial volume of the Delta Programme is 1100 million $€$. This budget covers only the costs for operation, maintenance and reconstruction in (primary) flood protection, national water management and fresh water supply. The grand total of yearly water management costs in the Netherlands including regional water management, water quality and drinking water supply add up to 6600 million $€$. About $85 \%$ of these costs are paid for by local taxation. Every year on Budget Day $\left(2^{\text {nd }}\right.$ Tuesday in September) the government publishes an updated edition of the Delta Programme, which looks ahead to the forthcoming year. The Delta Programme started in 2010 and delivered in 2014 a number of strategic Delta Decisions.

\subsection{Delta Decisions}

In September 2014, the Dutch Delta Commissioner advised the government to take decisions [1] on the following five aspects of the Delta Programme:

- $\quad$ flood risk management;

- freshwater;

- $\quad$ spatial adaptation;

- the IJssellake region;

- the Rhine-Meuse delta.

The Delta Decision on flood risk management proposes new agreements to protect the Netherlands from flooding, including new standards on the height and strength of dikes. These standards are based on the estimated probability of flooding and the expected impact of the flooding (casualties, damages, disruption).

\subsection{New safety standards}

The Delta Decision on flood risk management is focused on the new flood protection standards [1]. These new standards were set using a risk-based approach. The first step in deriving the new standards is the introduction of a basic safety level of $10^{-5}$ per year for the acceptable probability (per year, on a specific place) of a fatality due to flooding. This is the so-called local individual risk. The second step is to check whether a higher level of protection may apply for areas in which flooding could lead to large groups of casualties or significant economic losses. A higher protection level may also apply if vital functions are present, such as a nuclear power plant.

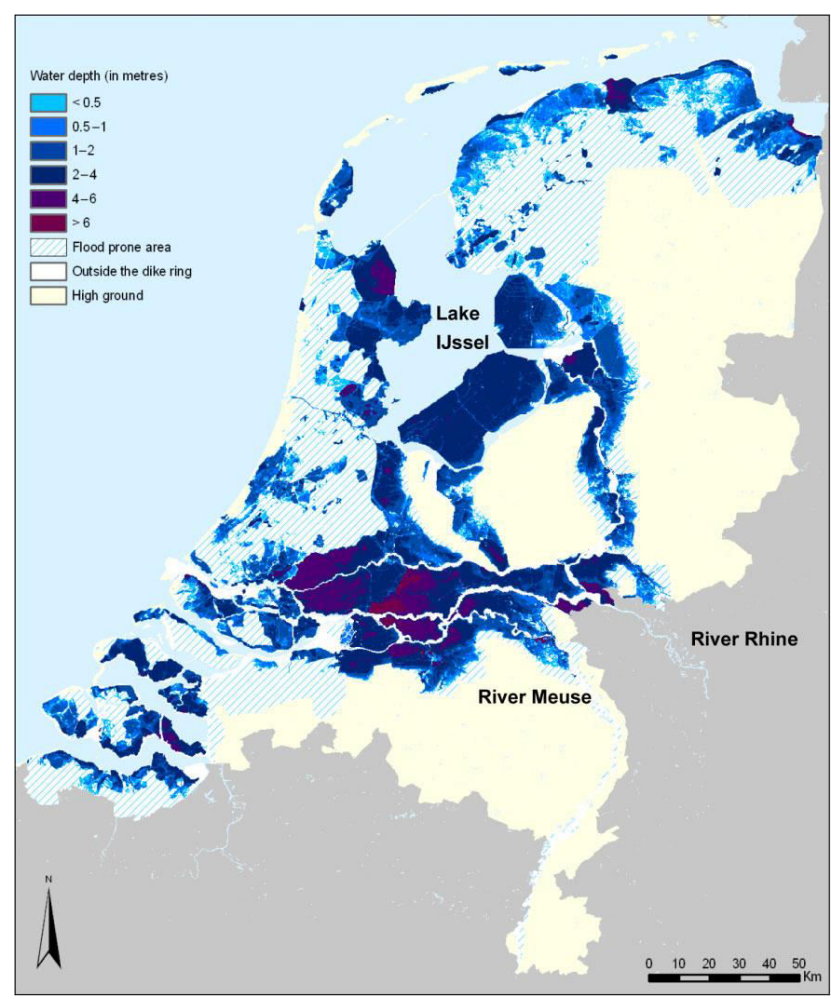

Figure 3 Flooding patterns [15]

The flood protection standards are derived using cost-benefit analysis and recently developed insights into flood risk assessment [14]. Especially the spatial variation of flooding pattern depending on the location of breaches in the flood protection structures has a significant influence on the risks [15]. Figure 3 shows the maximum water depth in metres in case of flooding.

These analyses result in economically efficient flood protection standards for different parts of the Netherlands that significantly differ from the present standards. Especially in the river area the new standards are stricter than the present standards. The optimization may also lead to different standards for flood protection structures surrounding the same dike ring area (if the consequences of flooding are different). The concept of multi-layered protection has been applied in deriving the safety standard: 
- Layer 1: measures to prevent flooding (like dikes, dams and dunes, but also creating more room for the rivers);

- Layer 2: counteracting the consequences of flooding through spatial planning;

- Layer 3: counteracting the consequences of flooding through emergency management.

Layer 3 has been taken into account using an evacuation rate depending on the type of flooding and dike ring area. Level 2 has been taken into account by anticipating on the spatial planning situation of 2050. The final result is the flood protection standard is expressed as the acceptable yearly probability of flooding due to a failed flood protection section (figure 4).

\section{Safety standards (flooding probability)

$\begin{array}{lll}-1 / 300 \text { per year } & 1 / 10000 \text { per year } \\ & 1 / 1000 \text { per year } \quad 1 / 30000 \text { per year } \\ & 1 / 3000 \text { per year } & -1 / 100000 \text { per year }\end{array}$

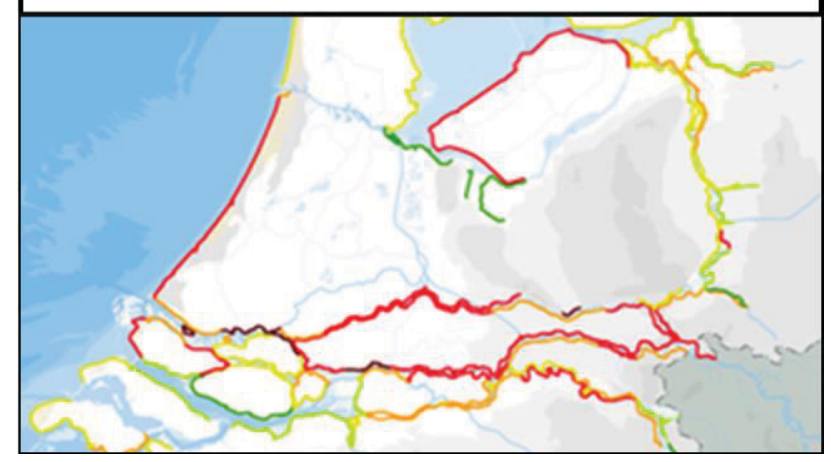

Figure 4 New safety standards [1]

The dimensions of these uniform sections range from 10-40 kilometres. These new standards will be laid down in law in 2017 and are to be met in 2050. The new safety standards range from $1 / 300$ per year to $1 / 100,000$ per year. The interval between safety assessments has been increased from 6 to 12 years. Following the Delta decisions the focus of the Delta Programme is shifting towards delivering the policy decisions in practice by adapting water management strategies and reconstruction projects.

\subsection{Delivering the new standards}

Following the Delta decisions the focus of the Delta Programme is shifting towards delivering the policy decisions in practice by adapting water management strategies and reconstruction projects. The reconstruction projects range from coastal and beach nourishment to preserve the required width and height of the dunes, creating more room for the rivers to allow for increased river discharges and to reinforce the primary flood protection structures (figure 5)
Rijkswaterstaat and the regional water authorities are responsible for delivering the new safety standards and the focus is on measures in layer 1 . In addition to measures in layer 1 Rijkswaterstaat and the regional water authorities cooperate with other authorities (provinces, municipalities) to increase performance in layers 2 and 3 . However, there are no binding agreements

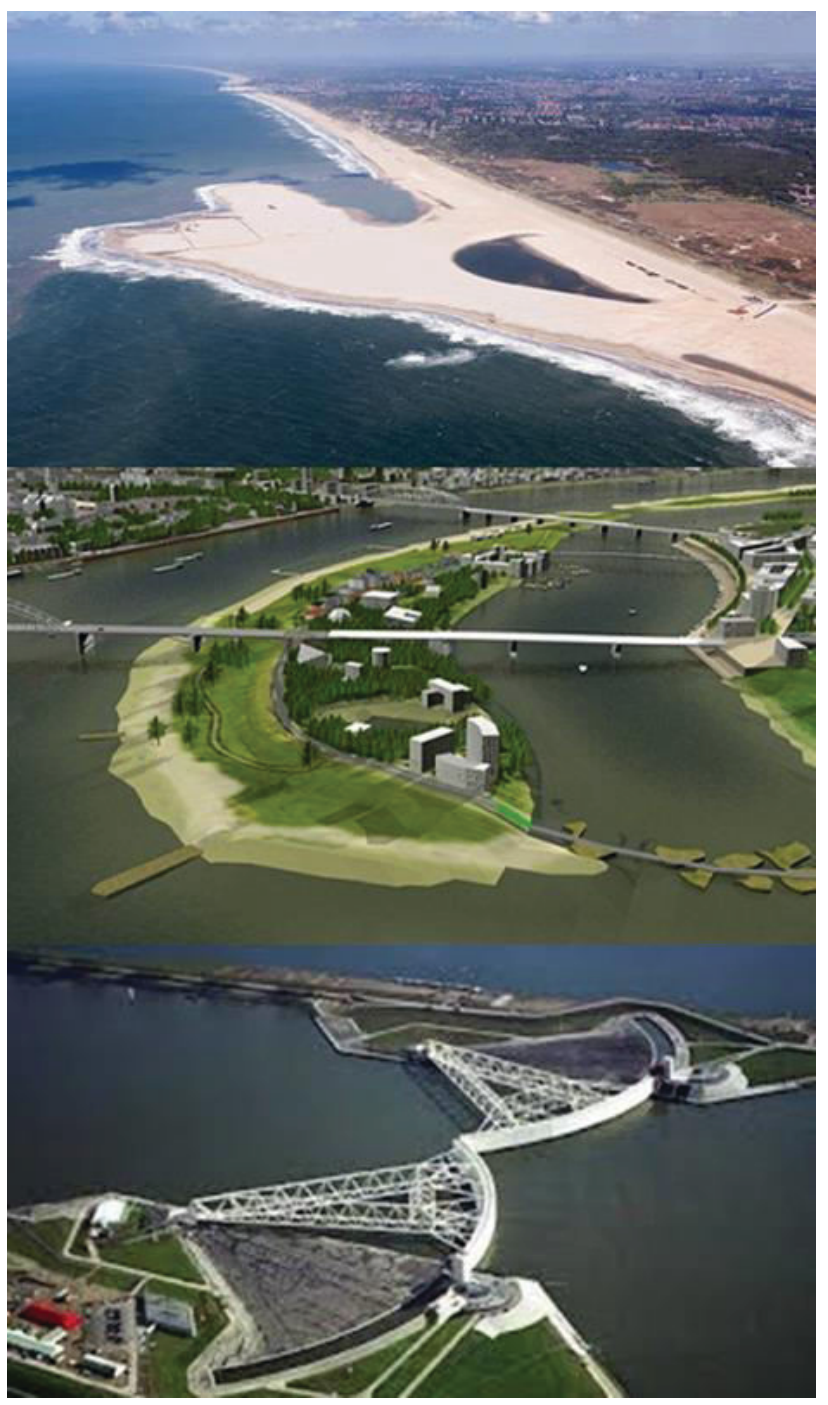

Figure 5 Delivering safety standards or standards for the performance in layers 2 and 3 .

The necessary reinforcement of the primary flood protection structures is organized by Rijkswaterstaat and the regional water authorities in the Dutch Flood Protection Programme. 


\section{Dutch Flood Protection Programme}

The Dutch Flood Protection Programme (DFPP) is a significant part of the Delta Programme. The DFPP is both an organization and a methodology. The organization is an alliance of the regional water authorities and Ministry based upon joint responsibility and financing of flood protection measures along the coast, rivers and lakes. Regional water authorities are responsible for the realization of the majority the projects within the DFPP. Regional water authorities and Rijkswaterstaat have installed a small joint organization to prepare the yearly reconstruction programme, to distribute the necessary funds for the projects, to monitor and report progress and to assist the regional water authorities and Rijkswaterstaat by organizing (applied) scientific research, training of professionals (e.g. risk based strategies, but also in project management), setting the quality standards for project management and organizing the distribution of knowledge and experience between all authorities involved (communities of practice).

The DFPP also stands for a methodology in which scientific institutes, consultancy and construction companies participate. The programme contains the (expected) projects for the next decades. The goal of the DFPP is to improve flood protection structures that do not meet the required safety standards. The initial scope of the DFPP is $748 \mathrm{~km}$, determined by the third safety assessment (completed in 2011-2013), but the new and generally stricter safety standards need to be taken into account as well. It is expected that the scope will expand to roughly $1900 \mathrm{~km}$ in order to reach these new standards. This massive scope is organized using risk assessment on various levels. On a national level the necessary projects are ranked based on the actual flooding risk (probability times the expected damages) and fitted within the budget constraints. Additional goals of the DFPP are to improve performance in project management, to enhance the quality of more integral solutions and to expand the cooperation between all authorities involved.

\section{Prioritizing the programme}

\subsection{Influx}

The influx for the programme is determined by the regular safety assessments. Regional water authorities and Rijkswaterstaat assess the actual safety of the embankments against the legal standards using up-to-date information and tools (hydraulic loads and technical criteria). According to the present safety standards each cross-section of the flood protection structures is tested for several failure mechanisms. The result of the test is rather digital: the cross-section meets the technical standard or it does not. There is however a small margin for interpretation and advanced testing (using additional field data or experimental information) can be applied. The results of the safety assessment are ascertained by the Minister of Infrastructure and Environment.

During the period 2011-2013 the third safety assessment yielded a grand total of 748 kilometres that didn't meet the (present) safety standards. Regional water authorities and Rijkswaterstaat proposed reinforcement projects.

\subsection{Risk based programming}

From 2020 onwards the yearly budget of 362 million $€$ yearly is fully dedicated to the DFPP. Between 2014-2020 the budget is to be shared with the earlier reinforcement programme initiated by the second safety assessment. Fitting the scope within the budget requires a prioritization method. It was decided that all proposed reinforcement projects would be ranked on the actual risk due to flooding (probability*consequences). However, due to the rather digital nature of the assessment procedure the estimation of the probability of flooding required an additional step. Using a simplified (compared to the full scale tools developed for the new safety standards [14]) tool the probabilities of flooding were classified, as were the consequences. Figure 6 shows the total scope of 748 kilometres ranked based in risks.

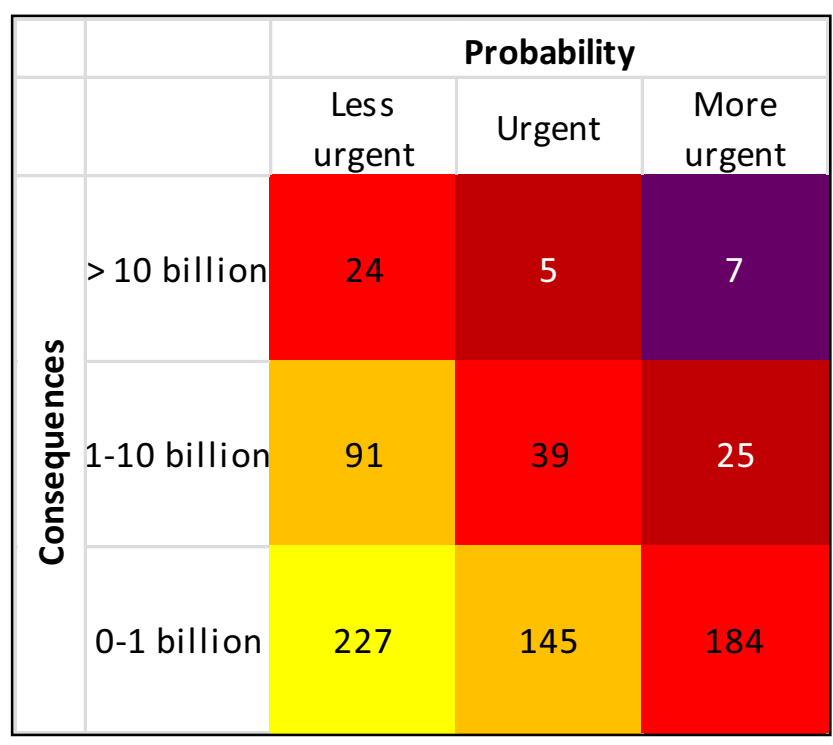

Figure 6 Risk based prioritization

The programming process itself is relatively straightforward: fitting the projects within the budget constraints. The initial planning and estimation of costs per project is based on experience and simplified models. In 2013 the first programme was prepared for the period 2014-2019 with over 40 projects (with a majority of exploration phases) and a total financial volume of 300 million $€$. 


\subsection{Changing to new safety standards}

Although the new safety standards will become statutory as of 2017, it was inevitable that the new standards would apply to the DFPP.

\subsubsection{New safety standards in projects}

The first step was to introduce the new safety standards for the reinforcement projects of the DFPP. The first projects would start their preparation phase in 2014 and construction was not expected to happen before 2018. This meant that the technical designs should be prepared based on the new standards. In 2014 the DFPP initiated a preliminary design guide that could be used for the dike reinforcement projects.

\subsubsection{New safety standards in the programme}

Introducing the safety standards in the programme is a more complicated matter. Technically the new standards would lead to a different ranking of the projects. The following figures illustrate the effect of ranking the present scope of 748 kilometres based on the present safety standards (figure 7 , as shown in section 5.2) and based on the new safety standards (figure 8).

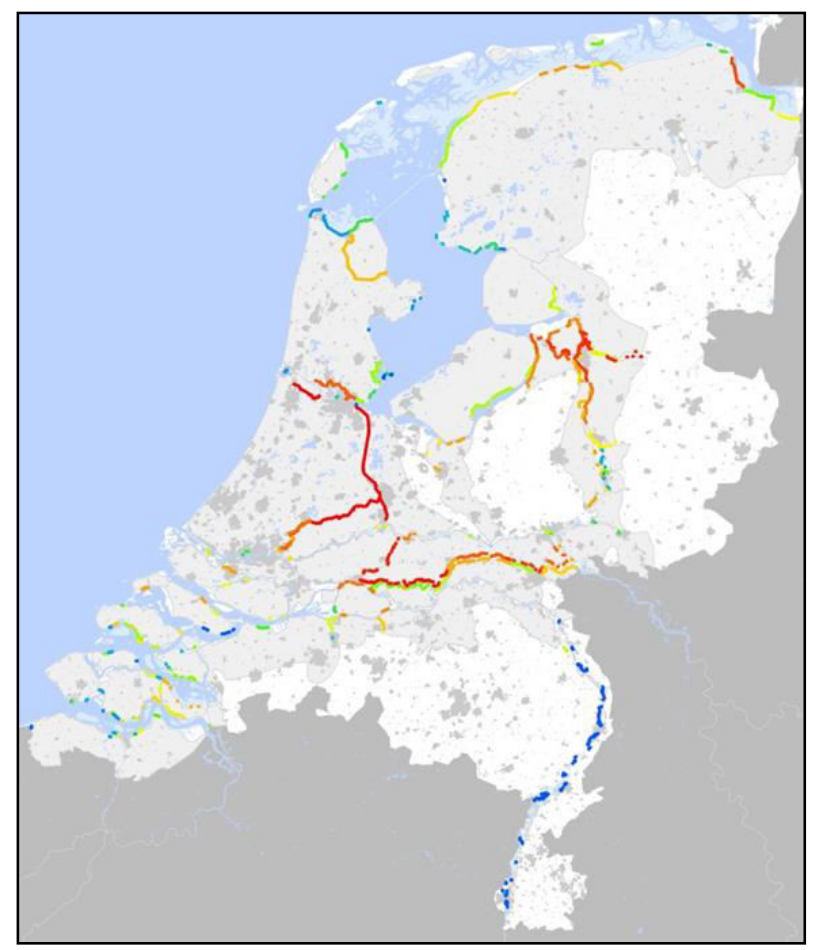

Figure 7 Present scope - present ranking

The new ranking is calculated simply by the distance between the actual probability of flooding and the new safety standard. For these calculations the results of an earlier research project were used [16].

Because the new standards yield more value (risk reduction) for money, this step should be taken as soon as possible. However, there are two reasons why this technical step can't be made very easily. The operational reason is that projects have been prepared and started during the period 2013-2016. Aborting these projects would be a waste of money and effort. Also the general public may get confused. The formal argument is that the new safety standards are not valid until 2017 . This means that the programme for the period 2017-2021could be based on the prioritization according to the new safety standards.

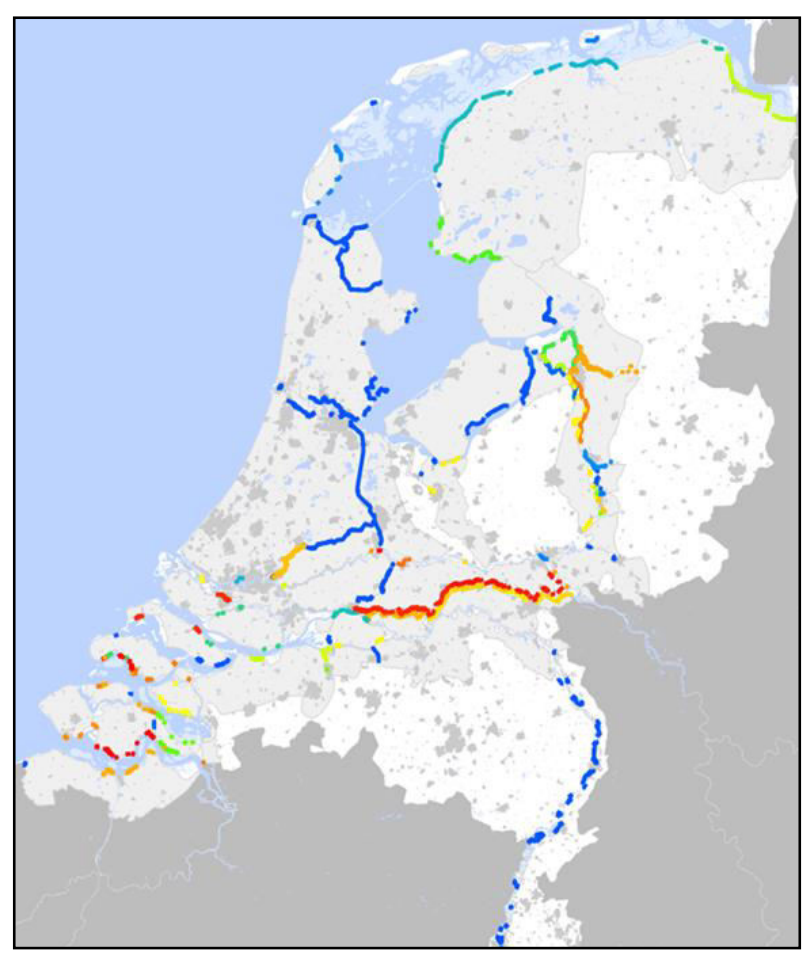

Figure 8 Present scope - new ranking

The preparation for the programme 2017-2022 has been completed at the end of 2015. This programme is based on the new safety standards (figure 9), but allows the projects from earlier programmes that already have been started to be completed.

The introduction of the new safety standards also have another significant effect. Flood protection structures may meet the present safety standard, but fail to comply with the much stricter new safety standards in some areas. However, the formal safety assessment according to the new safety standards still has to begin. The necessary instruments are being developed and the legislation is being prepared. Furthermore, the first safety assessment (1996-2001) showed that regional water authorities and Rijkswaterstaat needed time to gather the required data and get used to the instrument. It is likely that the fourth safety assessment (or: the first assessment for the new safety standards) will face the same introduction problems. This may lead to the situation that the most urgent projects (according to the new standards) will not enter the DFPP shortly after 2017.

To solve this issue the DFPP has ranked the actual probability of flooding of all new flood protection sections using the VNK2-tool [16]). The results (figure 9) 
are presented as a ranking of the 100 most urgent flood protection sections, discerning the present scope (already started projects and projects not started yet) and the expected scope in the near future. The graphs shows that two groups of urgent sections of the expected scope are not included in the present scope and are very likely to become urgent after the next safety assessment. The first group shows a probability of flooding at least 90 times higher than the new safety standard, whereas in the second group the probability is at least 30 times higher than the new safety standard.

The graph also shows that risk-based prioritization of the present scope generally fits the new prioritization using the ratio between the probability of flooding and the new safety standard. Only 6 projects of the present scope that weren't started yet are very urgent according to the new safety standards.

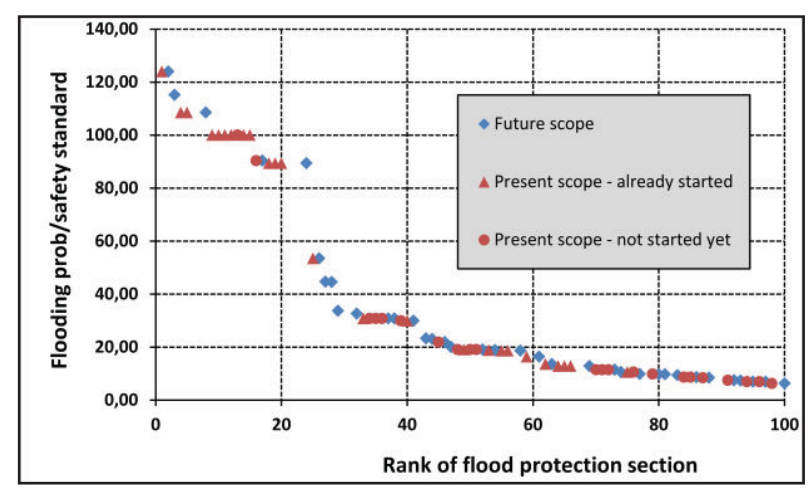

Figure 9 Future and present scope - new ranking

Based on this analysis it was decided to include the 13 projects of the future scope and the 6 projects of the present scope into the programme 2017-2022, although the formal safety assessment for the 13 projects hasn't been carried out yet. This decision enhances the overall performance of the DFPP (the new standards are more efficient) and eliminates the risks associated to the introduction of the new safety assessment procedure.

\subsection{Results}

After 4 years the DFPP has produced their fourth programme for the period 2017-2022. The total number of projects within the DFPP is now 70, covering more than 600 kilometres and about two billion $€$. Given the recent start of the DFPP no output results can be shown.

Both the projects and the programme as a whole are prepared for the new safety standards that were developed parallel to the initial stages of the DFPP. In the near future safety assessments of flood protection sections according to the new standard will be carried out. Based on the results of these assessments the scope of the DFPP will change gradually.

The prioritization based on risk (or for the new standards based on the distance between the actual safety and the required standard) leads to a transparent programme. The downside however is that some regional water authorities are faced with an enormous task whereas others are scheduled (much) later in the programme. Sharing resources between the various authorities may contribute to effectiveness and efficiency.

\section{Effectiveness and efficiency}

\subsection{Programme goals}

The DFPP is not only aimed at realizing flood protection projects. The following comprehensive goals are relevant:

- $\quad$ increasing the production rate (effectiveness) of flood protection projects;

- improving efficiency of flood management by reducing the costs per kilometre;

- enhancing the societal value of flood protection projects;

- improving the cooperation between the authorities involved;

- assuring the quality and control of both the programme and the projects.

Based on earlier reinforcement projects and programmes the historical reinforcement rate is approximately 25 kilometres per year. In order to complete the task of roughly 1900 kilometres by the year 2050 this rate must go up to an average of around 50 kilometres per year.

A similar exercise can be made regarding to costs of reinforcing flood protection structures. During the last decades the average cost per kilometres in The Netherlands has increased to 10 million $€$. Given the yearly budget of 360 million $€$ this figure has to go down again, to 7 million $€$ per kilometre.

Reinforcement projects may have a significant impact on the environment (nature, urban, societal). Minimizing the environmental impact of reinforcement project is not enough. The successful programme Room for the River [17] was aimed at both flood protection and enhancing spatial quality of the flood plains. Although spatial quality is not a formal goal of the DFPP, flood protection solutions can be designed in such a way that the societal value is maximized.

Regional water authorities are independent public authorities. Rijkswaterstaat is the executive body of the Ministry of Infrastructure and Environment. Both type of organizations have a lot to gain by cooperating. Typically, regional water authorities have excellent regional knowledge (for example in terms of subsoil characteristics) and Rijkswaterstaat is very experienced in project management, flood risk research and contracting strategies. 
Improving control of both projects and the programme as a whole is essential to keep the (public) support for the massive task ahead of us and associated funds.

\subsection{Incentives}

Earlier reinforcement projects and programmes were mostly carried out by the regional water authorities and fully subsidized by the Ministry. This arrangement didn't contribute to effectiveness and efficiency. For example, life cycle based solutions weren't taken into account, because the Ministry only subsidized reconstruction works. A smarter solution including additional maintenance or operational costs wasn't subsidized and therefore regional water authorities refrained from these type of solutions.

A similar effect was seen during the safety assessment. There was no incentive for the regional water authorities to invest in a comprehensive safety assessment. As a consequence a part of the scope of the DFPP still has to be optimized.

In the Governance Agreement on Water [12] the regional water authorities decided to co-finance the future reinforcement projects in order to improve effectiveness and efficiency. This led to two major changes in financing (and governance) of flood protection projects in the Netherlands.

First, the budget for flood protection projects is paid for by the Ministry (50\%) and all regional water authorities (40\%). The remainder of $10 \%$ is paid for by the regional water authority responsible for the project. If a project is carried out by Rijkswaterstaat, the budget is paid for by the Ministry.

The second major change in the financial incentive was on the topic of risk management. Risks associated with the realization of reinforcement projects are to be managed by the responsible authority (in most cases the regional water authority). Based on risk assessment a budget is included in the total project budget. Contracting risk and risk due to changes in regulations (such as the new safety standards) are not included in the project risk, but these risks are transferred to the programme.

\subsection{Adaptive programming}

Projects within the DFPP are carried out in three steps (after the necessary preparation steps such as a safety assessment). The first step is the exploration step: a wide range of alternative solutions is investigated and based on the desired effects of the optimal solution a socalled preference alternative is selected. This alternative is further investigated and designed during the planning step. The results of this step are laid down in spatial planning and contracting documents. The final step is the construction step.
The planning, financial estimates and risk assessment obviously do develop during the three steps. Therefore, these steps are financed consecutively by the DFPP. The developing estimates of time and costs are used to update the yearly programme.

\subsection{Innovations}

Innovations are essential to reach the overall programme goals. The innovation strategy of the DFPP has both a top-down and bottom-up approach. The topdown part is based on the (expected) scope of the programme. A large part of that scope is due to the dominant failure mechanisms macro-stability and piping. Measures to prevent these mechanisms are either quite expensive or require a lot of space. Innovations focused on these mechanisms are likely to be highly effective. Based on this assessment the DFPP has asked all parties involved (contracting companies, consultancy firms, public authorities, research institutes, universities, ..) to identify potential innovations. These proposals have been assessed and ranked according to the impact on the programme or the project (see figure 10). Especially the innovations on the right hand side (type II and III) are of interest to fulfil the programme goals.

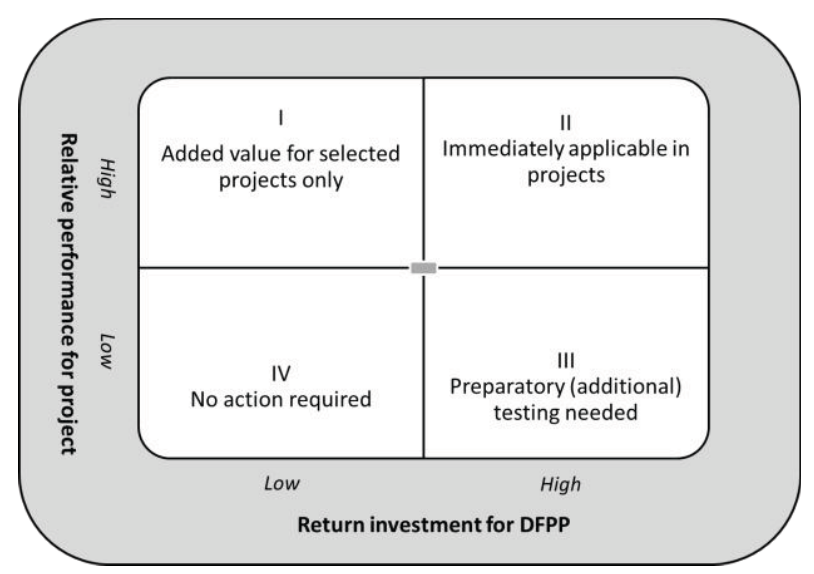

Figure 10 Ranking innovations

In the lower right of figure 10 the innovations are collected that need additional testing (preferable in the prototype), but that are very important for the performance of the programme because of the potential impact. For these innovations specific research and testing projects are initiated within the DFPP. At present there are technical research project for piping and macrostability.

The bottom-up approach of innovation is project based. Examples of these type of innovations are a movable barrier in an historic, urban environment and a multiple coastal dike combined with cockle farming.

Innovations are not limited to technical innovations. The DFPP also stimulates innovations on contracting, stakeholder participation and decision making. 
In order to stimulate innovation in general an additional incentive has been incorporated within the DFPP. For innovative projects the remainder of $10 \%$ is paid for by DFPP, but also the risks associated to the innovation are transferred to the programme. The DFPP does not have a separate innovation budget, for instance $2 \%$ of the total budget. This traditional approach doesn't stimulate enough the innovation in projects. So far, the different approach pays off: almost $25 \%$ of the budget is spent on innovative projects. The outcome in terms of reducing the costs of reinforcement projects can be shown later.

\section{Governance and organization}

\subsection{Water governance in general}

The governance of the DFPP is obviously only a part of the entire system of Dutch water governance. According to the OECD [18] this system is fit for purpose with some (future) challenges. With regard to flood management the most relevant challenge is to close the "awareness gap": Dutch citizens have a low perception of flooding risks. In the long run this may affect the willingness to pay for flood protection measures, but it also reduces the effectiveness of flood protection measures in layers 2 (spatial planning) and 3 (emergency management).

\subsection{Governance DFPP}

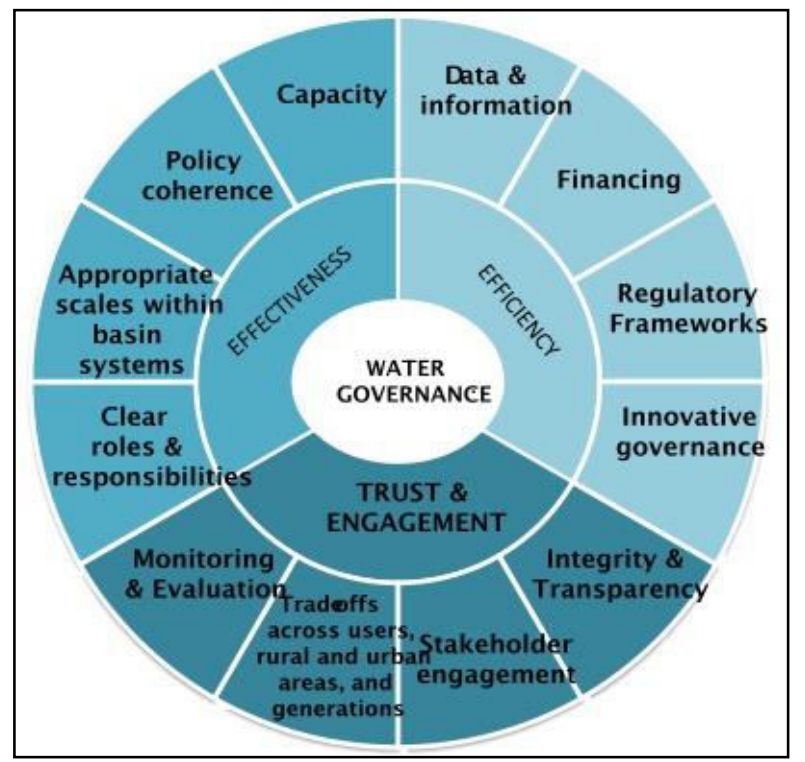

Figure 11 OECD Water governance principles

The governance of the DFPP was developed several years before the OECD Water governance principles [19] were published (figure 11). However, many of the OECD principles seem to be incorporated with a focus on effectiveness and efficiency.

\subsection{Organization DFPP}

The basic idea for the organisation of the DFPP is to respect the role and responsibilities of the Ministry and the regional water authorities as much as possible.

The Ministry is responsible for setting the flood protection policies, including the new safety standards. The Ministry also develops the tools for the safety assessment. And finally, 50\% of the budget for the DFPP is supplied by the Ministry. Within the Ministry Rijkswaterstaat is responsible for management and maintenance of the national infrastructure. For example, the large storm surge barriers and closure dams. Reinforcement projects of Rijkswaterstaat are a part of the DFPP but these projects are financed separately by the Ministry.

The joint programme team of the DFPP reports to a joint steering committee in which the Ministry, Rijkswaterstaat and the regional water authorities are represented. The steering committee advises the Minister by preparing the yearly programme that becomes part of the Delta Programme and the National Budget.

The programme team can remain small by using the strength of the partners in the alliance. For example, reviewing and assessing the quality of project proposals is carried out by teams of colleagues, communities of practice on certain topics are run by Rijkswaterstaat and the regional water authorities.

\section{Developments and discussion}

Now that the initial phase of the DFPP is behind us, an evaluation of the programme will be carried out. This evaluation is certainly not only focused on the past. A number of relevant developments need to be taken into account:

- Increasing volume of the programme;

- Growing demand for integral projects;

- Full implementation of new safety standards;

- Growing need for well-trained personnel;

- Coherent communication by the Ministry, Rijkswaterstaat and regional water authorities on projects and programme.

- Maintaining the solidarity between the regional water authorities and between the Ministry, Rijkswaterstaat and the regional water authorities.

The volume of the programme will increase the next few years to $50 \mathrm{~km} /$ year and a financial maximum of 360 million $€$ per year. This volume is by far the largest volume of dike reinforcement projects in the history of the Netherlands. On top of that, this volume is not a single peak, but needs to be realized every year until 2050 in order to meet the new safety standards. This 
means that the processes of the DFPP need to be optimized, refraining from bureaucracy and stimulating Rijkswaterstaat and the regional water authorities to improve on their performance.

There is a growing demand for integral projects, in which flood protection purposes are combined with other functions such as nature development, recreation, transport, housing etc. To combine this demand with a (flood) risk-based prioritization of the reinforcement projects is a challenge. By improving the strategic planning of flood protection projects it is possible to start the local discussions on the desired scope of the projects much earlier. Now, these discussions are part of the (pre) exploration step of the projects, which can be just a couple of years before construction starts. This period is often too limited for other potential partners in the project to arrange their decision making on scope and finances. From 2017, the new safety assessments offers the opportunity for Rijkswaterstaat and regional water authorities to predict the scope and planning of their flood protection projects in a much earlier stage. This will enhance the possibilities to find the best societal scope of the project without losing sight of the flood protection goals.

In 2017 the new safety standards will become statutory. This marks the end of two decades of research and policy preparation. It is also the beginning of a new era where safety assessment procedures and design manuals need to be rewritten. Especially the design manuals will change completely. The present manuals reflect the experience of decades working with the present safety standards. These standards are technically based on service limit states; in fact the actual structural failure (breaching) is not included in the present design practice. The new safety standards are directly based on flood risk and therefore expressed as an acceptable probability of structural failure, the so-called ultimate limit state. This requires different design criteria that are not readily available.

Both the size of the programme and the new technical developments, combined with the aging of present staff of Rijkswaterstaat and the regional water authorities require an impulse on capacity building. Training existing staff, exchanging experiences and sharing resources are not enough. Strategic personnel planning based on the long term programme shows that the public authorities need about 500 well-trained people to run all the projects. Obviously, in this figure the need of the private industry (consulting and contracting) is not included. Therefore, the DFPP will start to contribute to education in order to promote working in flood protection, the project and the programme.

The awareness gap about flood risks in The Netherlands needs to be bridged. This is a major challenge for regional water authorities, Rijkswaterstaat and the Ministry. The DFPP can contribute to bridging the gap by developing a more relevant communication strategy, both for laymen and professionals, both national and international. Overview, innovation and integral solutions will be elements of this strategy. Overview linking all flood protection activities together is important and creates frequent interactions. Innovation is a key message for both the general public and professional actors (researcher, consultants and constructors). Integral solutions illustrate the new approach of flood protection structures: not about flood protection only, but also about landscape and society. Together these messages highlight a new generation of flood protection structures as the reinvention of a Dutch tradition.

In 2023 the Governance Agreement on Water will be evaluated. Obviously, the performance of the programme will also be evaluated. But another important issue of the evaluation will be the solidarity, both between the regional water authorities and between the regional water authorities, the Ministry and Rijkswaterstaat.

The solidarity between the regional water authorities is about the balance between the costs and the benefits of the programme. The costs are rather straightforward: every regional water authority contributes to the programme (roughly $10 €$ per inhabitant per year), but some regional water authorities do not have any flood protection issues. Some of them do not even have flood protection structures. The benefits of the programme need to be clear. Efficiency and effectiveness are important, but the spinoff of the programme (education, innovation, capacity building, ..) will become important too.

The solidarity between the regional water authorities, the Ministry and Rijkswaterstaat is more about complementarity. The organizations and their role will remain different and it is important that the DFPP mobilizes the strengths of all authorities involved in order to compensate for their weaknesses.

\section{References}

1. Ministry of Infrastructure and Environment and Ministry of Economic Affairs, Dutch Delta Programme 2015, Working on the Delta, the decisions to keep the Netherlands safe and liveable, September 2014.

2. Alphen, J. van, The Delta Programme and updated flood risk management policies in the Netherlands, 6th International Conference on Flood Management (ICFM6), September 2014, Sao Paulo, Brazil

3. Netherlands Environmental Assessment Agency, Correction wording flood risks for the Netherlands in IPCC-report, www.pbl.nl/en/dossiers/Climatechange/content/corre ction-wording-flood-risks. Accessed February 2016

4. Pleijster, E.J. \& van der Veeken, C. (2015), Dikes of the Netherlands, LOLA Landscape Architects,, The Netherlands. 
5. Van Dantzig, D., Economic decision problems for flood prevention, Econometrica, 24, 276-287, The Netherlands 1956.

6. Van Dantzig, D. and Kriens, J., Het economische beslissingsprobleem inzake de beveiliging van Nederland tegen stormvloeden, Rapport van de Deltacommissie, The Netherlands, 1960

7. Jorissen, R.E., Safety, risk and flood protection, Proceedings of the RIBAMOD Workshop 1 on Current Policy and Practice in Flood Management, Eds R Casale, G B M Pedroli \& P G Samuels, published by the Directorate General for Research and Development, European Commission, Luxembourg, ISBN 92-828-2002-5, 1998

8. Jorissen, R.E., Litjens-van Loon, J. and Mendez Lorenzo, A., Flooding risk in coastal areas. Risk, safety levels and probabilistic techniques in five countries along the North Sea coast, Ministry of Transport, Public Works and Water Management, The Netherlands, 2001.

9. Hofstede, J. et al, Common strategies to reduce the risk of storm floods in coastal lowland, report COMRISK, Schleswig-Holstein State Ministry of Agriculture, Environment and Rural Areas, Germany, 2005

10. Hegger, C. et al, Flood Risk Management in Europe - similarities and differences between the STARFLOOD consortium countries, report WP1 STARFLOOD, Utrecht University, The Netherlands, 2013.

11. Ten Heuvelhof et al, Een dijk van een programma: Naar een nieuwe aanpak van het Hoogwaterbeschermingsprogramma, 2010

12. Governance Agreement on Water, The Netherlands, 2011

13. Veerman, C., Working together with water; A living land builds for its future, The Netherlands, 2008.

14. Kind, J., Economically efficient flood protection standards for the Netherlands, Journal Flood Risk Management 7 103-117, 2014.

15. De Bruijn K.M. \& Van der Doef M., Gevolgen van overstromingen- Informatie ten behoeve van het project Waterveiligheid 21e eeuw Projectnumber 1204144. Deltares, Delft, The Netherlands, 2011.

16. Jongejan R.B., The VNK2-project: quantifying flood risks in the Netherlands. Proc. PSAM12/ESREL. 2529 Jun, Helsinki, Finland, 2012.

17. Rijke, J., Herk van, S., Zevenbergen, C., Ashley R.. Room for the river: delivering integrated river basin management in the Netherlands. International Journal of River Basin Management 10:4, 369-382, 2012.

18. OECD Studies on Water, Water governance in the Netherlands - Fit the Future?, 2014.

19. OECD Principles on Water Governance, Directorate for Public Governance and Territorial Development, Welcomed by Ministers at the OECD Ministerial Council Meeting on 4 June 2015. 